\title{
Testing the Dynamic Linkages of the Pakistani Stock Market with Regional and Global Markets
}

\section{Zohaib Aziz ${ }^{*}$ and Javed Iqbal ${ }^{* *}$}

\begin{abstract}
This article examines the dynamic linkages between Pakistan's emerging stock market and (i) the US market and (ii) the regional markets of India and Japan. Using data for the daily returns and volatility spillovers of three market pairs (Pakistan-US, Pakistan-Japan and Pakistan-India), the study estimates a series of bivariate asymmetric $\operatorname{VARMA}(1,1)-G A R C H(1,1)$ models. It also fits multivariate asymmetric VARMA(1,1)-GARCH(1,1) models for two groups of markets: Pakistan-India-US and Pakistan-India-Japan. Based on the mean spillovers, the results suggest that the global and regional equity markets (Granger) cause the Pakistani market. There are unidirectional volatility spillovers to Pakistan from the US and Japan, while India is the only regional market with a significant crossasymmetric effect on Pakistan. In the multivariate case, the regional and global markets have significant joint mean and variance spillovers and asymmetric effects on the Pakistani market. This indicates a weak degree of integration between the Pakistani market and the global and regional markets, implying that local risk factors - either firm-specific or country-specific - explain the expected returns on investment in the Pakistani stock market.
\end{abstract}

Keywords: Dynamic linkages, bivariate GARCH, financial market integration.

JEL classification: G15, F65.

\section{Introduction}

The increasing integration of international financial markets has attracted the attention of financial analysts, multinational and domestic firms, investors, traders, portfolio managers, researchers, governments,

\footnotetext{
* Department of Statistics, Federal Urdu University of Arts, Sciences and Technology.

** University of Karachi and Institute of Business Administration, Karachi.

The authors would like to thank the participants of the 6th South Asian International Conference (SAICON) held in Islamabad (11-13 August 2014) for their valuable comments. They are also grateful to the Federal Urdu University of Arts, Sciences and Technology for financial support via the Dean Science Research Grant (2014/15).
} 
international economic and financial policymakers and market regulators. Stock market integration occurs when the stock markets of different countries move in tandem, i.e., their returns and volatility are driven by common shocks. These dynamic linkages may be weak or strong and the degree of interdependence explains whether investors can move easily between markets and whether there are arbitrage opportunities to be availed (Jawadi \& Arouri, 2008).

Investigating the strength and direction of co-movements between international stock markets is an important area of research. Several factors drive the integration of international markets, including (i) an increase in international trade and finance between national economies; (ii) open-door policies of liberalization that allow international investors to participate in local markets; (iii) technological advancements in communication and the gradual elimination of limits in capital flows; and (iv) the contagion effects of international financial crises. Analyzing the integration of stock markets may be useful for asset pricing and allocation, risk diversification, trading and hedging strategies, and the regulation of capital markets.

Analyzing the extent of integration helps gauge risk reduction through portfolio diversification. When a national market is weakly integrated with global markets, the transmission of returns and volatility shocks is limited. Thus, the inclusion of such weakly integrated markets in an investment portfolio gives international investors the benefits of diversification. In contrast, when markets are fully integrated, international financial and economic conditions strongly influence domestic markets. This increases the risk exposure of portfolios and limits the diversification benefits to international investors. Thus, investors tend to seek portfolios including stock markets that are not integrated or are weakly integrated with global markets so that the portfolio risk is smaller.

Stock market integration also has important implications for market efficiency. If the past returns of a stock market can be used to predict changes in other stock markets, then we cannot consider a semi-strong form of market efficiency to hold, according to Fama's (1970) classifications. Emerging markets tend to have higher levels of volatility and associated returns than developed markets (Iqbal, 2012). The linkages between emerging markets and mature markets make the former more sensitive and volatile. These linkages and transmissions are analyzed using the mean returns and volatility spillovers. 
It is also worth investigating which mature or developing markets are closely linked to local emerging markets. Accordingly, the interdependency of emerging markets with global and regional markets is an important area in the finance literature. More recently, technological developments have become an additional channel of financial market linkages, making the regulation of financial markets more challenging as regulators must keep an eye on external developments. Studying dynamic linkages becomes especially important in crisis periods (e.g., the recent global financial crisis of 2008) when the intensity of external linkages is increased.

Very few studies in this area are based on South Asia. Specifically, there is little literature analyzing the linkages between markets at global and local levels with Pakistan as a base market and using rigorous econometric modeling such as the multivariate GARCH (MGARCH) approach. Barring a few studies, the literature provides no detailed testing of own and crossmean and volatility spillovers between markets. The extent and magnitude of spillovers and the direction of linkages has not been systematically investigated in this context, nor have models been compared in the analysis of integration effects.

Given this, our objective is to analyze the integration of emerging stock markets, specifically the linkages between Pakistan and other developed and developing stock markets (global and regional markets), including spillover magnitude and direction. This study gauges the extent to which the Pakistani stock market is influenced by global markets (the US), neighbor developing markets (India) and regional developed markets (Japan).

We include the US market, given its leading role in world financial markets and the 'global center hypothesis', which argues that global centers such as the US market play a major role in the transmission of shocks $(\mathrm{Li}$, 2007). As a large regional market, India has attracted investors' attention in recent years. Iqbal (2012) reports that the correlation between the Pakistani and Indian markets is 0.26 , which he deems nontrivial. It is also the second largest magnitude of correlation between Pakistan and the other countries in his sample. Given the size and importance of the Indian market, one would expect some shocks to the Pakistani market from global markets to be transmitted via the Indian market. Finally, Japan is a regional developed market and it is worth investigating whether volatility spillovers into Pakistan are more likely to be transmitted from a global center (the US) or a regional center (Japan). 
To achieve this objective, we use market pairs with Pakistan in a bivariate GARCH model and groups of countries with Pakistan in a trivariate model. We focus on the largest Pakistani stock market, the Karachi Stock Exchange (KSE), in which the KSE 100 is the most important index tracking aggregate stock price movement in Pakistan.

Iqbal (2012) provides an overview of the Pakistani stock market, explaining how it is integrated with world markets. He also examines correlation, pricing errors, cointegration and vector autoregressive (VAR) techniques used by other studies to measure integration in different periods. Earlier market integration analyses have used different versions of asset pricing models, while more recent studies tend to rely on econometric techniques (Chancharat, 2009). The literature on stock market integration, therefore, draws frequently on asset pricing models, Granger causality and cointegration techniques, factor analysis and GARCH models.

Some studies assume a linear dependence between markets and employ tests based on the constant correlation of index returns. However, the idea of time variations in volatility has now become more common, implying that stock market integration involves both linear and nonlinear dependence. Increasing stock market volatility is manifested in large stock price changes with either sign (Schwert, 1990). Accordingly, we employ a bivariate GARCH model that estimates linear and nonlinear dependence simultaneously to model mean returns and volatility.

The remaining article is organized as follows. Section 3 describes the methodology used. The data and primary diagnostics are given in Sections 4 and 5. Section 6 presents the study's results. Section 7 concludes.

\section{Literature Review}

Sharma and Seth (2012) provide a comprehensive literature review of stock market integration in which they characterize empirical studies by year, country, the number of countries comprising the study sample, the number of years considered in the sample dataset and the econometric and noneconometric methodologies adopted for the data analysis. They find that, although the literature has looked at stock market integration since the 1980s, the bulk of this work has been done in the last few years.

Despite the rising number of empirical studies on stock market integration, most studies have focused on developed - rather than emerging - markets. This can entail determining mean returns, volatility spillovers 
and the cross-market effect of the same country and different countries, using an MGARCH model. ${ }^{1}$ Several studies, however, examine the transmission of returns and volatility shocks from developed markets to Asian markets. These are outlined below.

$\mathrm{Li}$ (2007) tests the transmission of returns and volatility between the emerging stock market of China, the regional developed market of Hong Kong and the US global market, using a BEKK-MGARCH model. He finds no direct linkage between the Chinese and US markets and a unidirectional weak relationship with the Hong Kong market. Worthington and Higgs (2004) find nonhomogenous mean spillovers from developed markets and higher own-volatility spillovers compared to cross-volatility spillovers for the East and Southeast Asian markets, using a VAR(1)-BEKK $(1,1)$ model.

Using an MGARCH model, Chou, Lin and $\mathrm{Wu}$ (1999) find significant volatility spillovers from the US stock market to the Taiwan stock market, primarily in the close-to-open returns case. Miyakoshi's (2003) empirical results indicate that Asian markets are subject to a greater regional (Japan) influence than global (US) influence. In addition, the signals from a market that opens earlier provide useful information to Asian and international investors in terms of earning profits. In contrast to Miyakoshi, Li and Giles (2015) use an MGARCH model and find unidirectional shock and volatility spillovers from the US market to both the Japanese and Asian emerging markets.

Some studies focus on the dynamic linkages of European markets with major world markets. Li and Majerowska (2008) model and test the dynamic linkages between the emerging stock markets of Poland and Hungary and the developed markets of Germany and the US. They use a four-variable asymmetric GARCH-BEKK model and find evidence of weak integration among these markets. Saleem (2009) also uses a GARCH-BEKK model to investigate the relationship between the Russian equity market and world markets; he finds there is partial integration between the two.

Other studies use a geographically broader set of markets. Beirne et al. (2010) examine the mean and volatility spillovers of global and regional markets for a sample of 41 local emerging stock markets in Asia, Europe, Latin America and the Middle East. They analyze cross-market effects using tri-variate VAR-GARCH(1,1)-in-mean models and report significant spillovers from global and regional markets to local emerging markets.

\footnotetext{
${ }^{1}$ See Sharma and Seth (2012) and Chancharat (2009) for a detailed analysis of stock market integration.
} 
Kumar (2013) applies a VAR and MGARCH model to investigate the relationship of mean and volatility spillovers between stock prices and exchange rates for India, Brazil and South Africa. Using daily data, he finds evidence of bidirectional volatility spillovers in the stock and foreign exchange markets and argues that stock markets play a relatively important role in these spillovers.

In contrast to the studies above, which focus on linkages in emerging markets in Asia, Europe and Latin America, Karolyi (1995) uses a bivariate GARCH model to test the transmission of stock returns and volatility between two neighboring developed markets - Canada and the US. He finds far weaker returns and volatility spillovers in later subperiods, especially for those Canadian stocks that are listed dually on the New York Stock Exchange.

\section{Methodology}

We examine the bivariate and tri-variate linkages between Pakistan and three other stock markets - the US (a global developed market), Japan (a regional developed market) and India (a neighboring developing market) - to gauge the extent of regional and global integration effects on the former. This entails estimating and testing the mean returns and volatility spillovers between pairs of markets: Pakistan-US, Pakistan-Japan and Pakistan-India, using a bivariate GARCH model, and Pakistan-India-US and PakistanIndia-Japan, using an MGARCH model.

\subsection{MGARCH Model}

The MGARCH model is a useful tool to capture the transmission effects of mean and volatility spillovers between stock markets. It enables one to model and predict the time-varying volatility and volatility comovements of multivariate time series (Zivot \& Wang, 2005). Most MGARCH applications are related to asset returns and exchange rates.

Several specifications of the conditional variance-covariance matrix of the MGARCH model are used to capture integration effects. ${ }^{2}$ The BEKK model proposed by Engle and Kroner (1995) is an important specification of the MGARCH conditional variance-covariance, a key feature being its positive definiteness. However, as Tse and Tsui (2002) point out, interpreting the BEKK model parameters is not as easy as for other

\footnotetext{
2 See Bauwens, Laurent and Rombouts (2006) for a survey of different specifications of the MGARCH model.
} 
MGARCH modifications. Moreover, its accumulated effects on future variances and covariances are difficult to determine. Nonetheless, it remains a popular model, which this study uses to examine volatility dynamics.

Black (1976) argues that, with the same absolute magnitude, negative shocks have a larger impact on volatility than positive shocks - this is termed the leverage effect. Similarly, in the multivariate case, the variances and covariances may respond differently to positive and negative shocks (see Bauwens et al., 2006). Accordingly, Kroner and Ng (1998) propose an extension of the BEKK model that allows for the leverage effect. A bivariate $\operatorname{VARMA}(1,1)-\operatorname{BEKK}(1,1)$ model allowing asymmetric effects is given as follows:

$$
\begin{aligned}
& R_{t}=\Lambda+\Psi R_{t-1}+\Omega u_{t-1}+u_{t}, u_{t} \mid I_{t-1} \sim\left(0, H_{t}\right) \\
& H_{t}=\Gamma^{\prime} \Gamma+\Theta^{\prime} u_{t-1} u_{t-1}^{\prime} \Theta+\Phi^{\prime} H_{t-1} \Phi+D^{\prime} \xi_{t-1} \xi_{t-1}^{\prime} D \\
& R_{t}=\left[r_{1, t} r_{2, t}\right]^{\prime} \text { is the percentage log-returns vector. } u_{t}=\left[u_{1, t} u_{2, t}\right]^{\prime} \text { is }
\end{aligned}
$$
the residual vector with a conditional variance-covariance matrix $H_{t}=$ $\left[h_{i j, t}\right]_{i, j=1,2} \cdot \xi_{t}$ is equal to $u_{t}$ if $u_{t}$ is negative and 0 otherwise. The set of information available at time $t-1$ is expressed by $I_{t-1} \cdot \Lambda=\left[\lambda_{1} \lambda_{2}\right]^{\prime}, \Psi=$ $\left[\psi_{i j}\right]_{i, j=1,2}$ and $\Omega=\left[\omega_{i j}\right]_{i, j=1,2}$ are the coefficient matrices of constant terms, first-lagged returns and first-lagged shocks for the mean returns, respectively. The parameter matrix of volatility equation (2) is denoted by $\Gamma=\left[\gamma_{i j}\right]_{i, j=1,2^{\prime}}$ which is an upper triangular matrix. $\Theta=\left[\theta_{i j}\right]_{i, j=1,2}$ and $\Phi=\left[\phi_{i j}\right]_{i, j=1,2}$ are unrestricted $\mathrm{ARCH}$ and $\mathrm{GARCH}$ coefficient matrices, respectively. $D=$ $\left[d_{i j}\right]_{i, j=1,2}$ is the unrestricted coefficient matrix of the asymmetric response of volatility (see the Appendix for the model in expanded notation).

Equation (1) is used to assess the own and cross-mean returns spillover; equation (2) captures the own and cross-volatility spillover of the stock market. We use a multivariate student $t$-distribution for the residuals of the model.

\subsection{Estimation}

The parameters of the BEKK-MGARCH model are estimated by computing the multivariate conditional $\log$-likelihood function $L(\Omega)$ given by:

$$
L_{t}(\Omega)=-\log 2 \pi-\frac{1}{2} \log \left|H_{t}\right|-\frac{1}{2} u_{t}^{\prime}(\Omega) H_{t}^{-1}(\Omega) u_{t}(\Omega)
$$




$$
L(\Omega)=\sum_{t=1}^{T} L_{t}(\Omega)
$$

where $\Omega$ represents the vector of all unknown parameters and $T$ is the total number of observations of each series of returns vector $R_{t}$. The BerndtHall-Hall-Hausman numerical maximization algorithm is used to produce the maximum likelihood estimates of the parameters and associated standard errors.

\subsection{Model Diagnostics: Multivariate Portmanteau Test}

Hosking (1980) generalizes the univariate Ljung-Box test into a multivariate version - the multivariate portmanteau test, which considers all series simultaneously rather than separately as well as cross-moment serial correlations. The Hosking test statistic testing for no correlation, autocorrelation and cross-correlation in the residual vector series $u_{t}$ is given by:

$$
Q_{k(m)}=T^{2} \sum_{l=1}^{m} \frac{1}{T-l} \operatorname{tr}\left(\hat{\Xi}_{l}^{\prime} \hat{\Xi}_{0}^{-1} \hat{\Xi}_{l} \hat{\Xi}_{0}^{-1}\right)
$$

where $k$ is the dimension of returns vector $R_{t}, T$ is the total number of observations, $m$ is the maximum lag length and $\operatorname{tr}($.) is the trace function of the matrix, which is the sum of the diagonal elements of a square matrix. The estimated correlation matrix at lag $-l$ is denoted by $\hat{\Xi}_{l}=\left[\hat{\xi}_{i j}\right]_{i, j=1,2}$. Assuming the null hypothesis holds, $Q_{k(m)}$ follows asymptotically a chisquared distribution with $\left(k^{2} m\right)$ degrees of freedom. We use the multivariate Ljung-Box test to gauge the model's adequacy.

\subsection{Hypothesis Test (Wald Test)}

The following Wald test is used to test the mean and volatility spillover and cross-market asymmetric response of volatility:

$$
W=[S \hat{\beta}]^{\prime}\left[S \operatorname{var}(\hat{\beta}) S^{\prime}\right]^{\prime}[S \hat{\beta}] \sim \chi^{2}(q)
$$

where $S$ is the parameter restriction matrix of order (dimension) $q \times k, q$ is the number of restrictions and $k$ is the number of regressors. $\beta$ is a vector of estimated parameters of order $(k \times 1)$ and $\operatorname{var}(\beta)$ is the heteroskedasticityrobust consistent estimator for the covariance matrix of the parameter estimates. 


\subsection{Mean and Volatility Spillover Tests}

We present 20 hypotheses, 16 of which represent all the pairs of countries - including a benchmark case and three mean and volatility spillover and cross-market asymmetric response cases - and four multivariate cases. The first parameter subscript denotes the Pakistani market. The second subscript denotes the country included in that pair. In the multivariate case, subscripts 1, 2 and 3 represent Pakistan, India and the US/Japan, respectively. Using the parameter notations given in the Appendix, we test the following hypotheses:

Joint tests of spillover in mean and variance and cross-market asymmetric effect

H01: No spillover in mean, no spillover in variance and no crossmarket asymmetric effect: $\psi_{12}=\psi_{21}=\omega_{12}=\omega_{21}=\theta_{12}=\phi_{12}=\theta_{21}=$ $\phi_{21}=d_{12}=d_{21}=0$

Tests of spillover in mean

- H02: No mean spillover: $\psi_{12}=\psi_{21}=\omega_{12}=\omega_{21}=0$

- H03: No mean spillover from the second market to the first: $\psi_{12}=$ $\omega_{12}=0$

- H04: No mean spillover from the first market to the second: $\psi_{21}=$ $\omega_{21}=0$

Tests of spillover in variance

- H05: No volatility spillover: $\theta_{12}=\phi_{12}=\theta_{21}=\phi_{21}=0$

- H06: No volatility spillover from the second market to the first: $\theta_{12}=$ $\phi_{12}=0$

- H07: No volatility spillover from the first market to the second: $\theta_{21}=$ $\phi_{21}=0$

- H08: No ARCH effect spillover: $\theta_{12}=\theta_{21}=0$

- H09: No ARCH volatility spillover from the second market to the first: $\theta_{12}=0$

- H10: No ARCH volatility spillover from the first market to the second: $\theta_{21}=0$

- H11: No GARCH volatility spillover: $\phi_{12}=\phi_{21}=0$ 
- H12: No GARCH volatility spillover from the second market to the first: $\phi_{12}=0$

- H13: No GARCH volatility spillover from the first market to the second: $\phi_{21}=0$

Tests of cross-market asymmetric effect in variance

- H14: No cross-market asymmetric response: $d_{12}=d_{21}=0$

- H15: No cross-market asymmetric response from the second market to the first: $d_{12}=0$

- H16: No cross-market asymmetric response from the first market to the second: $d_{21}=0$

Tests for multivariate case

- H17: No spillover in mean, variance and cross-market asymmetric effect on the Pakistani market: $\psi_{12}=\psi_{13}=\omega_{12}=\omega_{13}=\theta_{12}=\phi_{12}=$ $\theta_{13}=\phi_{13}=d_{12}=d_{13}=0$

- H18: No joint mean spillover from the regional and global markets to the Pakistani market: $\psi_{12}=\psi_{13}=\omega_{12}=\omega_{13}=0$

- H19: No joint volatility spillover from the regional and global markets to the Pakistani market: $\theta_{12}=\phi_{12}=\theta_{13}=\phi_{13}=0$

- H20: No joint cross-market asymmetric response from the regional and global markets to the Pakistani market: $d_{12}=d_{13}=0$

These 20 hypotheses are performed to test the own and cross-mean and volatility spillovers and determine any linear and nonlinear dynamic linkages between the Pakistani market and the other markets. Since dynamic linkages can stem from different sources, it is important to test this aspect. In this respect, the study provides a much broader coverage of tests than earlier studies.

\section{Data}

The sample of countries being tested for their relationship with Pakistan are India, the US and Japan. We use the daily closing index prices on the KSE 100 (Karachi Stock Exchange), the BSE Sensex 30 (Bombay Stock Exchange), the Nikkei 225 (Tokyo Stock Exchange) and the S\&P 500 (New York Stock Exchange) to represent the stock markets of Pakistan, India, Japan and the US, respectively. The data for each country consists of 3,115 
value-weighted index observations - the closing prices adjusted for dividends and splits - for the period 3 July 1997 to 13 November 2012. We delete all same-date observations for these markets if any observation is missing on account of no trading. Thus, we consider the observations for those dates on which all the markets were open. The percentage daily log returns for the given indices are employed by taking the first difference of the $\log$ indices and multiplying them by 100 , i.e., $r_{t}=\left(\ln P_{t}-\ln P_{t-1}\right) \times 100$.

All the data has been obtained from Datastream. Given that Japan is part of this study, it is worth noting that the Asian financial crisis of 1997 may render the estimation less useful. However, on rechecking the results after excluding the crisis period by starting the sample from January 1998, we find there is no significant change.

\section{Descriptive Statistics and Primary Diagnostics}

Table 1 reports the percentage daily log returns for the four stock markets. We can see that the average returns for the emerging markets in the sample are greater than those for the developed markets. Pakistan has the highest average return ( 0.025 percent) and Japan the lowest ( -0.020 percent). As evident from the standard deviations, India is found to be the most volatile market with a standard deviation of 1.63 percent, while the US market is the least volatile, with a standard deviation of 0.58 percent. Barring India, the market returns exhibit negative skewness, indicating that large negative stock returns are more common than large positive returns.

The kurtosis results in Table 1 show that the distributions of the emerging markets, Pakistan and India, are more leptokurtic than those of the developed markets, the US and Japan. This excess kurtosis indicates that extreme returns or outliers appear more frequently in emerging markets than in developed ones. The Jarque-Bera statistics reflect the nonnormality of all four distributions. The descriptive statistics reported here endorse the stylized facts of financial returns. The GARCH model is equipped to deal with data that exhibits this feature. Moreover, the nonzero skewness suggests an ARCH order greater than 1 (see Li, 2007). The $\operatorname{GARCH}(1,1)$, which is equivalent to an $\mathrm{ARCH}(\infty)$ model, is a parsimonious statistical model. 
Table 1: Percentage daily log returns, 3 July 1997 to 13 November 2012

\begin{tabular}{lllll}
\hline & \multicolumn{1}{c}{ Pakistan } & \multicolumn{1}{c}{ India } & Japan & \multicolumn{1}{c}{ US } \\
\hline Mean & 0.025 & 0.045 & -0.020 & 0.001 \\
Median & 0.057 & 0.098 & -0.005 & 0.026 \\
Maximum & 5.542 & 15.989 & 7.655 & 2.663 \\
Minimum & -5.738 & -11.809 & -11.153 & -4.003 \\
Standard deviation & 0.723 & 1.632 & 1.487 & 0.538 \\
Skewness & -0.347 & 0.119 & -0.308 & -0.377 \\
Kurtosis & 8.920 & 8.616 & 6.111 & 6.941 \\
Jarque-Bera statistic & $4,612.299$ & $4,101.286$ & $1,305.638$ & $2,090.471$ \\
P-value & 0.000 & 0.000 & 0.000 & 0.000 \\
\hline
\end{tabular}

Source: Authors' estimates.

\section{Results and Discussion}

Our analysis is based on the results presented in Tables 2 and 3. Table 2 reports the estimated results for the bivariate asymmetric $\operatorname{VARMA}(1,1)$ GARCH $(1,1)$ models with BEKK specifications for three pairs of markets Pakistan-US, Pakistan-India and Pakistan-Japan - using a multivariate student $\mathrm{t}$-distribution of errors. The results are divided into three panels: panels $A$ and $B$ give the estimates and standard errors of $\mathrm{AR}, \mathrm{MA}, \mathrm{ARCH}$, GARCH and the asymmetric coefficient matrices, while panel $C$ reports the diagnostics of the estimated models. The multivariate Ljung-Box $Q$ statistics for the third and sixth orders in squared standardized residuals show that there is no serial dependence in the latter. This indicates that the fitted variance-covariance equations are appropriate for all the pairs.

\subsection{Mean Equation Analysis}

Panel A of Table 2 shows that current returns are significantly predicted by past-day returns in the Pakistani market. The returns have positive first-order autocorrelation, which is evident from all the pairs of countries. The magnitude of past lags ranges from 0.9 to 0.977 . The Pakistani market has significant mean reversion as yesterday's unexpected positive shock decreases today's return significantly. The effect (response) of the previous day's shock on current returns ranges from 0.86 to 0.94 . 
Table 2: Estimated coefficients for bivariate asymmetric GARCH model and its diagnostics

\begin{tabular}{|c|c|c|c|}
\hline \multirow[t]{2}{*}{ Parameter } & \multicolumn{3}{|c|}{ VARMA(1,1)-BEKK(1,1) } \\
\hline & Pakistan-US & Pakistan-India & Pakistan-Japan \\
\hline \multicolumn{4}{|c|}{ Panel A: Estimated coefficients of mean equations } \\
\hline$\lambda_{1}$ & $\begin{array}{l}0.002 \\
(0.002)\end{array}$ & $\begin{array}{l}0.008^{* * *} \\
(0.004)\end{array}$ & $\begin{array}{l}0.011^{* *} \\
(0.005)\end{array}$ \\
\hline$\lambda_{2}$ & $\begin{array}{l}0.005 \\
(0.004)\end{array}$ & $\begin{array}{l}0.0454 \\
(0.036)\end{array}$ & $\begin{array}{l}0.061^{* * *} \\
(0.034)\end{array}$ \\
\hline$\psi_{11}$ & $\begin{array}{l}0.901^{*} \\
(0.029)\end{array}$ & $\begin{array}{l}0.975^{*} \\
(0.066)\end{array}$ & $\begin{array}{l}0.977^{*} \\
(0.066)\end{array}$ \\
\hline$\psi_{12}$ & $\begin{array}{l}0.214 \\
(0.139)\end{array}$ & $\begin{array}{l}-0.101 \\
(0.091)\end{array}$ & $\begin{array}{l}-0.112 \\
(0.078)\end{array}$ \\
\hline$\psi_{21}$ & $\begin{array}{l}0.052 \\
(0.040)\end{array}$ & $\begin{array}{l}0.610 \\
(0.390)\end{array}$ & $\begin{array}{l}0.481 \\
(0.397)\end{array}$ \\
\hline$\psi_{22}$ & $\begin{array}{l}0.514^{*} \\
(0.182)\end{array}$ & $\begin{array}{l}-0.186 \\
(0.246)\end{array}$ & $\begin{array}{l}-0.073 \\
(0.216)\end{array}$ \\
\hline$\omega_{11}$ & $\begin{array}{l}-0.863^{*} \\
(0.033)\end{array}$ & $\begin{array}{l}-0.940^{*} \\
(0.070)\end{array}$ & $\begin{array}{l}-0.933^{*} \\
(0.069)\end{array}$ \\
\hline$\omega_{12}$ & $\begin{array}{l}-0.155 \\
(0.130)\end{array}$ & $\begin{array}{l}0.121 \\
(0.095)\end{array}$ & $\begin{array}{l}0.127 \\
(0.082)\end{array}$ \\
\hline$\omega_{21}$ & $\begin{array}{l}-0.055 \\
(0.042)\end{array}$ & $\begin{array}{l}-0.612 \\
(0.388)\end{array}$ & $\begin{array}{l}-0.444 \\
(0.396)\end{array}$ \\
\hline$\omega_{22}$ & $\begin{array}{l}-0.563^{*} \\
(0.175)\end{array}$ & $\begin{array}{l}0.268^{*} \\
(0.242)\end{array}$ & $\begin{array}{l}0.162 \\
(0.215)\end{array}$ \\
\hline \multicolumn{4}{|c|}{ Panel B: Estimated coefficients of variance and covariance equations } \\
\hline$\gamma_{11}$ & $\begin{array}{l}0.118^{*} \\
(0.010)\end{array}$ & $\begin{array}{l}0.129 * \\
(0.009)\end{array}$ & $\begin{array}{l}0.126^{*} \\
(0.010)\end{array}$ \\
\hline$\gamma_{21}$ & $\begin{array}{l}-0.009 \\
(0.010)\end{array}$ & $\begin{array}{l}-0.030 \\
(0.043)\end{array}$ & $\begin{array}{l}0.091^{* * *} \\
(0.053)\end{array}$ \\
\hline$\gamma_{22}$ & $\begin{array}{l}0.052^{*} \\
(0.006)\end{array}$ & $\begin{array}{l}0.310^{*} \\
(0.028)\end{array}$ & $\begin{array}{l}0.435^{*} \\
(0.035)\end{array}$ \\
\hline$\theta_{11} 1$ & $\begin{array}{l}0.370^{*} \\
(0.025)\end{array}$ & $\begin{array}{l}0.326^{*} \\
(0.025)\end{array}$ & $\begin{array}{l}0.355^{*} \\
(0.025)\end{array}$ \\
\hline$\theta_{21}$ & $\begin{array}{l}0.078^{*} \\
(0.017)\end{array}$ & $\begin{array}{l}0.001 \\
(0.008)\end{array}$ & $\begin{array}{l}0.021^{*} \\
(0.007)\end{array}$ \\
\hline$\theta_{12}$ & $\begin{array}{l}0.023^{* * *} \\
(0.012)\end{array}$ & $\begin{array}{l}-0.118^{* *} \\
(0.047)\end{array}$ & $\begin{array}{c}-0.195^{*} \\
(0.055)\end{array}$ \\
\hline$\theta_{22}$ & $\begin{array}{l}0.055^{* * *} \\
(0.033)\end{array}$ & $\begin{array}{l}-0.140^{*} \\
(0.029)\end{array}$ & $\begin{array}{l}0.192^{*} \\
(0.024)\end{array}$ \\
\hline$\phi_{11}$ & $\begin{array}{l}0.882^{*} \\
(0.008)\end{array}$ & $\begin{array}{l}0.883^{*} \\
(0.009)\end{array}$ & $\begin{array}{l}0.892^{*} \\
(0.009)\end{array}$ \\
\hline
\end{tabular}




\begin{tabular}{|c|c|c|c|}
\hline \multirow[t]{2}{*}{ Parameter } & \multicolumn{3}{|c|}{ VARMA(1,1)-BEKK $(1,1)$} \\
\hline & Pakistan-US & Pakistan-India & Pakistan-Japan \\
\hline \multirow[t]{2}{*}{$\phi_{21}$} & $0.015^{* *}$ & $0.007^{* * *}$ & $-0.010^{* *}$ \\
\hline & $(0.007)$ & $(0.003)$ & $(0.004)$ \\
\hline \multirow{2}{*}{$\phi_{12}$} & -0.001 & -0.006 & 0.012 \\
\hline & $(0.006)$ & $(0.024)$ & $(0.026)$ \\
\hline \multirow{2}{*}{$\phi_{22}$} & $0.958^{*}$ & $0.916^{*}$ & $0.877^{*}$ \\
\hline & $(0.003)$ & $(0.008)$ & $(0.012)$ \\
\hline \multirow{2}{*}{$d_{11}$} & $0.337^{*}$ & $0.407^{*}$ & $0.340^{*}$ \\
\hline & $(0.039)$ & $(0.035)$ & $(0.036)$ \\
\hline \multirow[t]{2}{*}{$d_{21}$} & 0.009 & $-0.018^{* * *}$ & -0.009 \\
\hline & $(0.030)$ & $(0.010)$ & $(0.011)$ \\
\hline \multirow[t]{2}{*}{$d_{12}$} & -0.006 & 0.084 & $0.262^{*}$ \\
\hline & $(0.014)$ & $(0.058)$ & $(0.061)$ \\
\hline \multirow{2}{*}{$d_{22}$} & $-0.362^{*}$ & $0.450^{*}$ & $0.427^{*}$ \\
\hline & $(0.019)$ & $(0.029)$ & $(0.032)$ \\
\hline \multicolumn{4}{|c|}{ Panel C: Diagnostics } \\
\hline \multirow[t]{2}{*}{$\mathrm{LB}(3)$} & 12.401 & 7.252 & 15.741 \\
\hline & $(0.414)$ & $(0.840)$ & $(0.203)$ \\
\hline \multirow[t]{2}{*}{$\mathrm{LB}(6)$} & 21.892 & 19.072 & 24.211 \\
\hline & $(0.585)$ & $(0.748)$ & $(0.449)$ \\
\hline \multirow[t]{2}{*}{ LB2(3) } & 16.466 & 6.496 & 28.416 \\
\hline & $(0.170)$ & $(0.889)$ & $(0.004)$ \\
\hline \multirow[t]{2}{*}{ LB2(6) } & 24.150 & 13.448 & 40.024 \\
\hline & $(0.453)$ & $(0.958)$ & $(0.021)$ \\
\hline Log likelihood & $-4,685.834$ & $-8,184.977$ & $-8,207.943$ \\
\hline AIC & $9,423.668$ & $16,421.955$ & $16,467.887$ \\
\hline $\mathrm{BIC}$ & $9,580.803$ & $16,579.090$ & $16,625.022$ \\
\hline
\end{tabular}

Note: ${ }^{*},{ }^{* *},{ }^{* *}=$ significant at 1,5 and 10 percent, respectively. P-values given in parentheses.

LB and LB2 = multivariate Ljung-Box (portmanteau test) statistics for standardized and squared standardized residuals, respectively.

Source: Authors' estimates.

The cross-market return spillovers are captured by the off-diagonal parameters $\psi_{12}$ and $\psi_{21}$ of matrix $\Psi$ and $\omega_{12}$ and $\omega_{21}$ of matrix $\Omega$. The coefficients indicate that the regional and global markets have no significant impact on Pakistani returns. Similarly, no regional or global market return is influenced by the Pakistani market. The magnitude of the sum $\left(\psi_{12}+\omega_{12}\right)$ indicates the extent of anticipated and unanticipated shocks from the regional and global markets to the Pakistani market. These magnitudes show that a 1 percent increase in the past day's returns and shocks from the 
US, India and Japan increase current Pakistani returns by 0.0588 percent, 0.02 percent and 0.015 percent, respectively. The multivariate Ljung-Box $Q$ statistics for standardized residuals of the third and sixth orders (panel C, Table 2) indicate the appropriate specification of the mean equation for all considered cases. We also test the VAR models for mean equations of different orders, but their diagnostics are not satisfactory. The $\operatorname{VARMA}(1,1)$ model is found to be properly specified.

To ascertain the effect of the past day's own and cross-market anticipated and unanticipated shocks on current returns, we test several hypotheses. The results are reported in panels A and B of Table 3. The first question is whether any sort of local or foreign anticipated or unanticipated shocks affect current Pakistani returns. This hypothesis (H01) is easily rejected for all cases, which implies that the bivariate GARCH model is more suitable than the univariate GARCH model. The latter will be misspecified in the presence of significant cross-market effects.

Table 3: Wald test for restrictions on bivariate asymmetric GARCH model

\begin{tabular}{|c|c|c|c|}
\hline \multirow[t]{2}{*}{ Hypothesis } & \multicolumn{3}{|c|}{ Testing for restrictions } \\
\hline & Pakistan-US & Pakistan-India & $\begin{array}{c}\text { Pakistan- } \\
\text { Japan }\end{array}$ \\
\hline \multicolumn{4}{|c|}{$\begin{array}{l}\text { Panel A: Testing the combined restriction for mean and variance spillover and no cross- } \\
\text { market asymmetric effect (benchmark testing) }\end{array}$} \\
\hline \multicolumn{4}{|c|}{ H01: No spillover in mean and variance and no cross-market asymmetric effect } \\
\hline $\begin{aligned} \psi_{12}=\psi_{21}=\omega_{12} & =\omega_{21}=\theta_{12}=\phi_{12} \\
& =\theta_{21}=\phi_{21}=d_{12} \\
& =d_{21}=0\end{aligned}$ & $\begin{array}{l}62.924^{*} \\
(0.000)\end{array}$ & $\begin{array}{l}43.427^{*} \\
(0.000)\end{array}$ & $\begin{array}{l}38.572^{*} \\
(0.000)\end{array}$ \\
\hline \multicolumn{4}{|c|}{ Panel B: Wald test for testing the restrictions in mean equations of VARMA $(1,1)$} \\
\hline \multicolumn{4}{|c|}{ H02: No overall mean spillover } \\
\hline$\psi_{12}=\psi_{21}=\omega_{12}=\omega_{21}=0$ & $\begin{array}{l}21.260^{*} \\
(0.000)\end{array}$ & $\begin{array}{l}27.234^{*} \\
(0.000)\end{array}$ & $\begin{array}{l}17.441^{*} \\
(0.001)\end{array}$ \\
\hline \multicolumn{4}{|c|}{ H03: No mean spillover from the second market to the first } \\
\hline$\psi_{12}=\omega_{12}=0$ & $\begin{array}{l}20.238^{*} \\
(0.000)\end{array}$ & $\begin{array}{r}20.849^{*} \\
(0.000)\end{array}$ & $\begin{array}{l}13.074^{*} \\
(0.001)\end{array}$ \\
\hline \multicolumn{4}{|c|}{ H04: No mean spillover from the first market to the second } \\
\hline$\psi_{21}=\omega_{21}=0$ & $\begin{array}{c}1.672 \\
(0.433)\end{array}$ & $\begin{array}{c}2.478 \\
(0.289)\end{array}$ & $\begin{array}{c}4.122 \\
(0.127) \\
\end{array}$ \\
\hline
\end{tabular}




\begin{tabular}{lccc}
\hline Hypothesis & \multicolumn{3}{c}{ Testing for restrictions } \\
\cline { 2 - 3 } & Pakistan-US & Pakistan-India & $\begin{array}{c}\text { Pakistan- } \\
\text { Japan }\end{array}$ \\
\hline
\end{tabular}

Panel C: Testing the restrictions in $\operatorname{BEKK}(1,1)$ variance and covariance equations H05: No volatility spillover
$\theta_{12}=\phi_{12}=\theta_{21}=\phi_{21}=0$
$37.352^{*}$
$14.720^{*}$
7.401
(0.000)
(0.005)

H06: No volatility spillover from the second market to the first
$\theta_{12}=\phi_{12}=0$
$29.826^{*}$
3.884
$5.501^{* * *}$
(0.000)
$(0.143)$

H07: No volatility spillover from the first market to the second
$\theta_{21}=\phi_{21}=0$
$7.197^{* *}$
$11.686^{*}$
1.699
(0.027)
(0.002)

H08: No ARCH effect/spillover
$\theta_{12}=\theta_{21}=0$
$23.653^{*}$
$6.118^{* *}$
$6.621^{* *}$
(0.000)
(0.046)
(0.036)

H09: No ARCH effect spillover from the second market to the first
$\theta_{12}=01$
$20.279 *$
0.021
(0.000)
(0.883)
$5.264^{* *}$

H10: No ARCH effect spillover from the first market to the second
$\theta_{21}=0$
$3.745^{* *}$
$6.106^{* *}$
1.164
(0.052)
(0.013)
(0.280)

H11: No GARCH effect/volatility spillover
$\phi_{12}=\phi_{21}=0$
3.970
3.738
1.743
(0.137)
(0.154)

H12: No GARCH effect/volatility spillover from the second market to the first
$\phi_{12}=0$
$3.949 * *$
$3.738^{* * *}$
1.710
(0.046)
(0.053)
(0.190)

H13: No GARCH effect/volatility spillover from the first market to the second
$\phi_{21}=01$
0.088
0.061
0.062
$(0.765)$
(0.804)

H14: No cross-market asymmetric response
$d_{12}=d_{21}=0$
0.317
$5.415^{* * *}$
1.267
(0.853)
(0.066)
(0.530)

H15: No cross-market asymmetric response from the second market to the first
$d_{12}=0$
0.093
$3.207^{* * *}$
0.696
(0.759)
(0.073)
$(0.403)$

H16: No cross-market asymmetric response from the first market to the second
$d_{21}=0$
0.225
2.056
0.583
(0.635)
(0.151)
(0.444)

Note: ${ }^{*}{ }^{* *},{ }^{* * *}=$ significant at 1,5 and 10 percent, respectively. P-values given in parentheses.

Source: Authors' estimates. 
The hypothesis of no mean returns spillover to or from any of the local or foreign markets (H02) is rejected at 1 percent for all pairs of countries. The direction of this spillover effect is tested next. The hypothesis of a mean spillover (H03) from the second market to the Pakistani market is rejected, which implies that Pakistani market returns are significantly influenced by regional and global market shocks. As expected, the Pakistani market does not appear to have a significant influence on regional or global market returns (H04). This result makes sense, given that Pakistan is a far smaller market than the others.

As the World Bank data indicates, Pakistan's market capitalizationto-GDP ratio in 2012 was 19.5 percent, compared to 61.8 percent, 68 percent and 115.5 percent for Japan, India and the US, respectively. ${ }^{3}$ Moreover, Pakistan's economy is smaller than these economies. Next, we look at the spillover direction, which indicates unidirectional Granger causality from the regional and foreign market returns to the Pakistani market returns. This implies that the Pakistani market is not a semi-strong efficient form because it is affected by regional and global financial conditions. Since the magnitude of the mean spillover from the US market to the Pakistani market is greater than that of the regional market, our results are consistent with the global center hypothesis, which implies that a global center such as the US market plays a major role in the transmission of shocks (Li, 2007).

\subsection{Variance-Covariance Equation Analysis}

Panel B of Table 2 reports the estimated coefficients of the variancecovariance system.

\subsubsection{Volatility Persistence}

The sum of the GARCH coefficients, i.e., $\left(\phi_{11}+\phi_{12}\right)$ and $\left(\phi_{22}+\right.$ $\left.\phi_{21}\right)$, measures volatility persistence (see Li, 2007; Li \& Majerowska, 2008) for the first market (Pakistan) and the second market (the US, India or Japan). In the Pakistan-US case, the volatility persistence of the Pakistani and US markets is 0.881 and 0.973 respectively. Similarly, the volatility persistence of the Pakistan-India and Pakistan-Japan pairs is 0.8911 and 0.9103, and 0.8845 and 0.9566 , respectively. It is slightly lower for Pakistan than for the second market in each case, indicating that the Pakistani stock price index derives less of its volatility persistence from past volatility than from global markets (the US) or regional markets (India and Japan). Therefore, past

\footnotetext{
${ }^{3}$ www.worldbank.org
} 
shocks play a greater role in the volatility of the Pakistani market stock index than the other global and regional markets we have considered.

\subsubsection{Volatility Spillovers}

The cross-market volatility spillover in terms of the ARCH and GARCH effects is captured by the off-diagonal parameters $\theta_{12}$ and $\theta_{21}$ of ARCH matrix $\Theta$ and by $\phi_{12}$ and $\phi_{21}$ of GARCH matrix $\Phi$. The hypotheses associated with volatility spillovers are tested and reported in panel $\mathrm{C}$ of Table 3. The overall test of hypothesis H05 - no ARCH and GARCH volatility spillover between local markets and regional and global markets is rejected for all country pairs except for Pakistan-Japan.

Focusing on the direction of spillover, we test hypothesis H06 of no volatility spillover from the second market (the US, India or Japan) to the Pakistani market. We reject this hypothesis for the pairs related to the US and Japan. The neighboring Indian market does not seem to have an impact on the volatility of the Pakistani market. The Pakistani market's volatility is also driven by global forces since the statistical significance of the US pair is very strong. Interestingly, we are unable to reject H07 with respect to the volatility spillover from Pakistan to India. Thus, while the Indian market leads in terms of its impact on Pakistani stock returns, it is the Pakistani market's volatility that is found to influence that of the Indian market. The Pakistani market, therefore, has a volatility spillover toward all the markets considered except for Japan.

Hypotheses H08 to H13 test the nature of volatility shocks, i.e., whether they include a past volatility component (the GARCH component) or the squared shock of the past day (the ARCH component). Generally, the results show that unanticipated shocks (ARCH shocks) are more important in driving volatility spillover, as they are significant for all the pairs. Barring Japan, there seems to be bidirectional causality between the local Pakistani market and the regional and global markets. However, the GARCH spillover effects - from the regional and global markets to the Pakistani market - are also significant.

Hypotheses H14 to H16 test whether the impact of local anticipated and unanticipated past-day shocks is asymmetric, i.e., whether shocks related to bad news have more impact on current volatility than shocks associated with good news. The asymmetric elements $d_{12}$ and $d_{21}$ of matrix $\mathrm{D}$ in variance-covariance equation (3) capture the cross-market asymmetric effect. The results are interesting: Pakistani market volatility is related to the 
regional emerging market of India (H14). Bad-news events such as the 2008 Mumbai terrorist attacks are likely to have a much stronger effect on Pakistani volatility than good news from the Indian market. Its volatility appears to increase more in response to shocks associated with bad news from Pakistan than good news. Such asymmetric volatility responses do not emerge with respect to the developed markets of the US and Japan.

Our results reveal two important and related findings. First, the Pakistani market seems to operate more or less exogenously, as it receives smaller shocks from overseas markets relative to own local shocks. Earlier studies such as Aggarwal, Inclan and Leal (1999) and Rouwenhorst (1995) show that local factors are more important than global factors in affecting emerging market returns. In our case, such findings are manifested more in terms of volatility than returns per se since local shocks are associated with a much larger increase in volatility than shocks originating from the regional and global markets.

\subsubsection{Multivariate Spillovers}

Table 4 gives the estimated results for the multivariate asymmetric VARMA(1,1)-GARCH $(1,1)$ models with BEKK specifications for two sets of markets - Pakistan-India-US and Pakistan-India-Japan - using a multivariate student $t$-distribution of errors. Panels $A$ and $B$ of the table give the AR, MA, ARCH and GARCH estimates and the asymmetric coefficient matrices, respectively. Panel $C$ reports the diagnostics of the estimated models. The multivariate Ljung-Box Q statistics for the third and sixth orders of the squared standardized residuals show that there is no serial dependence in the latter, indicating the appropriateness of the fitted variance-covariance equations for all two sets. The subscripts $i=1$ and $i=2$ denote the Pakistani and Indian markets, respectively, while $i=3$ denotes the third market, i.e., the US or Japan. 
Table 4: Estimated coefficients for multivariate asymmetric GARCH model and its diagnostics

\begin{tabular}{|c|c|c|c|c|c|c|}
\hline \multirow[t]{3}{*}{ Parameter } & \multicolumn{6}{|c|}{ VARMA(1,1)-BEKK $(1,1)$} \\
\hline & \multicolumn{3}{|c|}{ Pakistan-India-US } & \multicolumn{3}{|c|}{ Pakistan-India-Japan } \\
\hline & $\begin{array}{l}\text { Pakistan } \\
(i=1)\end{array}$ & $\begin{array}{l}\text { India } \\
(i=2)\end{array}$ & $\begin{array}{l}\text { US } \\
(i=3)\end{array}$ & $\begin{array}{l}\text { Pakistan } \\
(i=1)\end{array}$ & $\begin{array}{l}\text { India } \\
(i=2)\end{array}$ & $\begin{array}{l}\text { Japan } \\
(i=3)\end{array}$ \\
\hline \multicolumn{7}{|c|}{ Panel A: Estimated coefficients of mean equations } \\
\hline$\lambda_{i}$ & $0.020^{* * *}$ & $0.122^{* * *}$ & 0.012 & 0.008 & 0.045 & 0.016 \\
\hline$\psi_{1 i}$ & $0.962^{*}$ & $-0.122^{* * *}$ & -0.407 & $0.956^{*}$ & -0.082 & -0.001 \\
\hline$\psi_{2 i}$ & 0.662 & -0.305 & $-3.029^{* *}$ & $0.671^{* * *}$ & -0.098 & -0.202 \\
\hline$\psi_{3 i}$ & -0.034 & 0.001 & $0.486^{* *}$ & $0.715^{* * *}$ & $-0.738^{* *}$ & $0.376^{* *}$ \\
\hline$\omega_{1 i}$ & $-0.929 *$ & $0.140^{* * *}$ & 0.472 & $-0.921^{*}$ & 0.098 & 0.010 \\
\hline$\omega_{2 i}$ & -0.663 & 0.349 & $3.520^{* *}$ & $-0.635^{* * *}$ & 0.174 & 0.206 \\
\hline$\omega_{3 i}$ & 0.035 & 0.007 & $-0.545^{* *}$ & $-0.682^{* * *}$ & $0.858^{* *}$ & $-0.450^{* *}$ \\
\hline \multicolumn{7}{|c|}{ Panel B: Estimated coefficients of variance and covariance equations } \\
\hline$\theta_{1 i}$ & $0.371^{*}$ & -0.065 & -0.010 & $0.337^{*}$ & $-0.086^{* *}$ & -0.019 \\
\hline$\theta_{2 i}$ & -0.011 & $0.090^{*}$ & $-0.012^{* *}$ & -0.007 & $-0.103^{*}$ & $-0.078^{*}$ \\
\hline$\theta_{3 i}$ & $0.073^{*}$ & $0.235^{*}$ & $-0.089^{*}$ & $-0.023^{*}$ & -0.005 & $0.095^{*}$ \\
\hline$\phi_{1 i}$ & $0.892^{*}$ & -0.014 & 0.001 & $0.892^{*}$ & -0.010 & -0.003 \\
\hline$\phi_{2 i}$ & -0.001 & $0.926^{*}$ & -0.002 & 0.003 & $0.930^{*}$ & $-0.019^{*}$ \\
\hline$\phi_{3 i}$ & $0.017^{* *}$ & 0.018 & $0.963^{*}$ & -0.002 & $-0.021^{*}$ & $0.969^{*}$ \\
\hline$d_{1 i}$ & $0.290^{*}$ & $0.161^{*}$ & -0.003 & $0.349^{*}$ & $0.112^{* *}$ & -0.034 \\
\hline$d_{2 i}$ & -0.005 & $0.401^{*}$ & 0.001 & $-0.019^{* * *}$ & $0.410^{*}$ & $0.051^{* *}$ \\
\hline$d_{3 i}$ & -0.025 & -0.021 & $0.318^{*}$ & 0.012 & 0.040 & $0.258^{*}$ \\
\hline \multicolumn{7}{|c|}{ Panel C: Diagnostics } \\
\hline $\mathrm{LB}(3)$ & \multicolumn{3}{|c|}{23.689} & \multicolumn{3}{|c|}{$\begin{array}{l}19.874 \\
(0.835)\end{array}$} \\
\hline $\mathrm{LB}(6)$ & \multicolumn{3}{|c|}{46.304} & \multicolumn{2}{|r|}{40.609} & $(0.911)$ \\
\hline LB2(3) & \multicolumn{3}{|c|}{22.922} & \multicolumn{3}{|c|}{26.852} \\
\hline LB2(6) & \multicolumn{3}{|c|}{$\begin{array}{l}42.026 \\
(0.881)\end{array}$} & \multicolumn{3}{|c|}{$\begin{array}{l}45.422 \\
(0.790)\end{array}$} \\
\hline $\begin{array}{l}\text { Log } \\
\text { likelihood }\end{array}$ & \multicolumn{3}{|c|}{$-10,123.539$} & \multicolumn{3}{|c|}{$-13,459.982$} \\
\hline AIC & \multicolumn{3}{|c|}{$20,357.079$} & \multicolumn{3}{|c|}{$27,029.964$} \\
\hline BIC & \multicolumn{3}{|c|}{$20,689.480$} & \multicolumn{3}{|c|}{$27,362.366$} \\
\hline
\end{tabular}

$*, * *, * * *=$ significant at 1,5 and 10 percent, respectively. P-values given in parentheses.

LB and LB2 = multivariate Ljung-Box (portmanteau test) statistics for standardized and squared standardized residuals, respectively.

Source: Authors' estimates. 
Table 5 gives the Wald test results for the joint restrictions of the MGARCH model fitted for two sets - Pakistan-India-US and Pakistan-IndiaJapan. The significance of hypothesis H17 in both MGARCH cases indicates the influence of the regional and global markets on the mean, variance and asymmetric effects of the Pakistani market. The rejection of hypotheses H18, H19 and H20 indicates joint significant cross-mean and variance spillovers and a cross-market asymmetric effect on Pakistan from either the regional markets (India and Japan) or the global market (the US). While these joint multivariate tests point to the general impact of the regional and global markets on the Pakistani market, the bivariate GARCH results are more indicative of the specific country and the extent of its influence over the Pakistani market.

Table 5: Wald test for restrictions on multivariate asymmetric GARCH model

\begin{tabular}{|c|c|c|}
\hline \multirow[t]{2}{*}{ Hypothesis } & \multicolumn{2}{|c|}{ Country groups } \\
\hline & Pakistan-India-US & Pakistan-India-Japan \\
\hline
\end{tabular}

H017: No joint spillover in mean or variance and cross-market asymmetric effect on Pakistani stock market

$$
\begin{aligned}
& \psi_{12}=\psi_{13}=\omega_{12}=\omega_{13}=\theta_{12}=\phi_{12} \\
& \begin{aligned}
=\theta_{13} & =\phi_{13}=d_{12}
\end{aligned}
\end{aligned}
$$

H18: No joint mean spillover from regional and global stock markets to Pakistani stock market
$\psi_{12}=\psi_{13}=\omega_{12}=\omega_{13}=0$
$37.491^{*}$
$23.490^{*}$
(0.000)
(0.000)

H19: No joint volatility spillover from regional and global stock market to Pakistani stock market
$\theta_{12}=\phi_{12}=\theta_{13}=\phi_{13}=0$
$8.516^{* * *}$
$10.151^{* *}$
(0.074)

H20: No joint cross-market asymmetric response from regional and global stock market to Pakistani stock market
$d_{12}=d_{13}=0$
$9.563^{*}$
$6.698^{* *}$
$(0.008)$
(0.035)

Note: ${ }^{*},{ }^{* * *}=$ significant at 1,5 and 10 percent, respectively. P-values given in parentheses.

Source: Authors' estimates.

\section{Conclusion}

The objective of this article was to investigate the spillover returns and volatility shocks from regional and global markets to the Pakistani stock market. We estimate a bivariate asymmetric VARMA $(1,1)-\operatorname{GARCH}(1,1)$ 
model with BEKK specifications to capture the mean and variance spillover channels for the pairs Pakistan-US, Pakistan-India and Pakistan-Japan and the groups Pakistan-India-US and Pakistan-India-Japan. The hypotheses tested through the mean and variance equation parameters analyze the different transmission channels between the Pakistani market and the regional and global markets.

We find evidence of unidirectional regional and global returns spillover toward Pakistan. The mean return of the Pakistani stock market depends on past-day returns and unanticipated shocks emanating from the regional and global markets. Thus, the global and regional equity markets Granger-cause the Pakistani market. The US market has the largest mean spillover to the Pakistani market while the regional markets have lower spillovers. However, the magnitude of the own-market spillover for Pakistan is greater than the cross-market spillover. The results of the mean returns show that asset prices in Pakistan are affected by regional and global business conditions. Our findings support the 'global center' hypothesis, which implies that the US market plays a vital role in transmitting news to the emerging market of Pakistan.

Although the Pakistani market has a high degree of volatility persistence in all cases, its volatility persistence magnitude is lower than that of the other markets. This suggests that volatility persistence stemming from past volatility for the Pakistani market has a smaller proportional effect on its share prices relative to the effect other markets have on their share prices. Thus, the volatility of the Pakistani stock market is derived more from past shocks than from other global or regional markets (the US, India and Japan).

The US and Japanese markets have unidirectional volatility spillovers toward the Pakistani market while the latter has a unidirectional volatility spillover toward India. We find that own-market volatility spillover is significant for Pakistan and more important than global volatility shocks. The past volatility of the (developed) US and Japanese markets is a source of current volatility in Pakistan, while the regional emerging market of India transmits its impact on Pakistani market volatility through unanticipated idiosyncratic (squared) shocks. The volatility of the Pakistani market increases more in response to past-day bad news from India than to good news of the same magnitude.

We also find that the current volatility of the Pakistani market is influenced primarily by past-day shocks, past-day volatility and own asymmetric effects. Foreign markets have very limited influence on the 
current value of Pakistani market volatility. This is evident from the magnitude of the own versus cross-market effects. The results indicate that the global market (the US) has the highest magnitude of cross-mean and volatility spillovers to the Pakistani market. The MGARCH tests confirm the findings of the bivariate tests and indicate that the regional and global markets have a significant impact on the mean, volatility and asymmetric volatility of the Pakistani stock market.

The Pakistani stock market is integrated with the global US market and regional Asian markets to some degree, but the small magnitude of global and regional market shocks suggests that the Pakistani stock market operates more or less exogenously. The impact of overseas shocks, while statistically significant, is economically very small. This low level of linkages would imply that the expected returns on investment in Pakistani stock exchanges are determined mainly by the country's exposure to local country-specific risk factors.

The news related to overseas development is less important. This weak integration of the Pakistani market makes it more suitable for inclusion in internationally diversified portfolios. Since the volatility of the Pakistani market can be predicted to some extent by past-day global and regional market shocks, we can conclude that the Pakistani market is not semi-strongform-efficient. Future research could focus on the nature of macroeconomic shocks and global financial crises with respect to the transmission of returns and volatility shocks to the local Pakistani market. 


\section{References}

Aggarwal, R., Inclan, C., \& Leal, R. (1999). Volatility in emerging stock markets. Journal of Financial and Quantitative Analysis, 34, 33-55.

Bauwens, L., Laurent, S., \& Rombouts, J. V. K. (2006). Multivariate GARCH models: A survey. Journal of Applied Econometrics, 21(1), 79-109.

Beirne, J., Caporale, G. M., Schulze-Ghattas, M., \& Spagnolo, N. (2010). Global and regional spillovers in emerging stock markets: A multivariate GARCH-in-mean analysis. Emerging Markets Review, 11(3), 250-260.

Black, F. (1976). Studies of stock market volatility changes. In Proceedings of the 1976 meeting of the Business and Economic Statistics Section, American Statistical Association (pp. 177-181). Washington, DC: American Statistical Association.

Chancharat, S. (2009). Stock market integration: An overview. NIDA Economic Review, 4(2), 23-35.

Chou, R. Y., Lin, J.-L., \& Wu, C. (1999). Modelling the Taiwan stock market and international linkages. Pacific Economic Review, 4(3), 305-320.

Engle, R. F., \& Kroner, K. F. (1995). Multivariate simultaneous generalized ARCH. Econometric Theory, 11(1), 122-150.

Fama, E. F. (1970). Efficient capital markets: A review of theory and empirical work. Journal of Finance, 25(2), 383-417.

Hosking, J. R. M. (1980). The multivariate portmanteau statistic. Journal of the American Statistical Association, 75(371), 602-608.

Iqbal, J. (2012). Stock market in Pakistan: An overview. Journal of Emerging Market Finance, 11(1), 61-91.

Jawadi, F., \& Arouri, M. H. (2008). Are American and French stock markets integrated? International Journal of Business and Finance Research, 2(2), 107-116. 
Karolyi, G. A. (1995). A multivariate GARCH model of international transmissions of stock returns and volatility: The case of the United States and Canada. Journal of Business and Economic Statistics, 13(1), $11-25$.

Kroner, K. F., \& Ng, V. K. (1998). Modeling asymmetric comovements of asset returns. Review of Financial Studies, 11(4), 817-844.

Kumar, M. (2013). Returns and volatility spillover between stock prices and exchange rates: Empirical evidence from IBSA countries. International Journal of Emerging Markets, 8(2), 108-128.

Li, H. (2007). International linkages of the Chinese stock exchanges: A multivariate GARCH analysis. Applied Financial Economics, 17(4), 285-297.

Li, H., \& Majerowska, E. (2008). Testing stock market linkages for Poland and Hungary: A multivariate GARCH approach. Research in International Business and Finance, 22(3), 247-266.

Li, Y., \& Giles, D. E. (2015). Modelling volatility spillover effects between developed stock markets and Asian emerging stock markets. International Journal of Finance and Economics, 20(2), 155-177.

Miyakoshi, T. (2003). Spillovers of stock return volatility to Asian equity markets from Japan and the US. Journal of International Financial Markets, Institutions and Money, 13(4), 383-399.

Saleem, K. (2009). International linkage of the Russian market and the Russian financial crisis: A multivariate GARCH analysis. Research in International Business and Finance, 23(3), 243-256.

Schwert, G. W. (1990). Stock returns and real activity: A century of evidence. Journal of Finance, 45(4), 1237-1257.

Sharma, A., \& Seth, N. (2012). Literature review of stock market integration: A global perspective. Qualitative Research in Financial Markets, 4(1), 84-122.

Tse, Y. K, \& Tsui, A. K. (2002). A multivariate generalized autoregressive conditional heteroscedasticity model with time-varying correlations. Journal of Business and Economic Statistics, 20(3), 351-362. 
Worthington, A., \& Higgs, H. (2004). Transmission of equity returns and volatility in Asian developed and emerging markets: A multivariate GARCH Analysis. International Journal of Finance and Economics, 9(1), 71-80.

Zivot, E., \& Wang, J. (2005). Modelling financial time series with S-PLUS, 2nd ed. Berline: Springer. 


\section{Appendix}

\section{Expansion of bivariate asymmetric VARMA(1,1)-GARCH(1,1)-BEKK model}

The mean equation is:

$$
\begin{aligned}
R_{t}=\Lambda+\Psi R_{t-1}+\Omega u_{t-1}+u_{t}, u_{t} \mid I_{t-1} \sim N\left(0, \Sigma_{t}\right) \\
{\left[\begin{array}{l}
r_{1, t} \\
r_{2, t}
\end{array}\right]=\left[\begin{array}{l}
\lambda_{1} \\
\lambda_{2}
\end{array}\right]+\left[\begin{array}{ll}
\psi_{11} & \psi_{12} \\
\psi_{21} & \psi_{22}
\end{array}\right]\left[\begin{array}{l}
r_{1, t-1} \\
r_{2, t-1}
\end{array}\right]+\left[\begin{array}{ll}
\omega_{11} & \omega_{12} \\
\omega_{21} & \omega_{22}
\end{array}\right]\left[\begin{array}{l}
u_{1, t-1} \\
u_{2, t-1}
\end{array}\right]+\left[\begin{array}{l}
u_{1, t} \\
u_{2, t}
\end{array}\right] } \\
\quad+\left[\begin{array}{l}
r_{1, t} \\
r_{2, t}
\end{array}\right]=\left[\begin{array}{l}
\lambda_{1} \\
\lambda_{2}
\end{array}\right]+\left[\begin{array}{l}
\psi_{11} r_{1, t-1}+\psi_{12} r_{2, t-1} \\
\psi_{21} r_{1, t-1}+\psi_{22} r_{2, t-1}
\end{array}\right]+\left[\begin{array}{l}
\omega_{11} u_{1, t-1}+\omega_{12} u_{2, t-1} \\
\omega_{21} u_{1, t-1}+\omega_{22} u_{2, t-1}
\end{array}\right] \\
{\left[\begin{array}{l}
r_{1, t} \\
r_{2, t}
\end{array}\right]=\left[\begin{array}{l}
\lambda_{1}+\psi_{11} r_{1, t-1}+\psi_{12} r_{2, t-1}+\omega_{11} u_{1, t-1}+\omega_{12} u_{2, t-1}+u_{1, t} \\
\lambda_{2}+\psi_{21} r_{1, t-1}+\psi_{22} r_{2, t-1}+\omega_{21} u_{1, t-1}+\omega_{22} u_{2, t-1}+u_{2, t}
\end{array}\right] } \\
r_{1, t}=\lambda_{1}+\psi_{11} r_{1, t-1}+\psi_{12} r_{2, t-1}+\omega_{11} u_{1, t-1}+\omega_{12} u_{2, t-1}+u_{1, t} \\
r_{2, t}=\lambda_{2}+\psi_{21} r_{1, t-1}+\psi_{22} r_{2, t-1}+\omega_{21} u_{1, t-1}+\omega_{22} u_{2, t-1}+u_{2, t}
\end{aligned}
$$

The variance-covariance equation is:

$$
H_{t}=\Gamma^{\prime} \Gamma+\Theta^{\prime} u_{t-1} u_{t-1}^{\prime} \Theta+\Phi^{\prime} H_{t-1} \Phi+D^{\prime} \xi_{t-1} \xi_{t-1}^{\prime} D
$$

where $\xi_{t-1}=u_{t-1}$ if $u_{t-1}<0$, and 0 otherwise.

$$
\begin{aligned}
{\left[\begin{array}{ll}
h_{11, t} & h_{12, t} \\
h_{21, t} & h_{22, t}
\end{array}\right]=} & {\left[\begin{array}{ll}
\gamma_{11} & 0 \\
\gamma_{21} & \gamma_{22}
\end{array}\right]^{\prime}\left[\begin{array}{ll}
\gamma_{11} & 0 \\
\gamma_{21} & \gamma_{22}
\end{array}\right] } \\
& +\left[\begin{array}{ll}
\theta_{11} & \theta_{12} \\
\theta_{21} & \theta_{22}
\end{array}\right]^{\prime}\left[\begin{array}{ll}
u_{1, t-1} \\
u_{2, t-1}
\end{array}\right]\left[\begin{array}{ll}
u_{1, t-1} & u_{2, t-1}
\end{array}\right]\left[\begin{array}{ll}
\theta_{11} & \theta_{12} \\
\theta_{21} & \theta_{22}
\end{array}\right] \\
& +\left[\begin{array}{ll}
\phi_{11} & \phi_{12} \\
\phi_{21} & \phi_{22}
\end{array}\right]^{\prime}\left[\begin{array}{ll}
h_{11, t-1} & h_{12, t-1} \\
h_{21, t-1} & h_{22, t-1}
\end{array}\right]\left[\begin{array}{ll}
\phi_{11} & \phi_{12} \\
\phi_{21} & \phi_{22}
\end{array}\right] \\
& +\left[\begin{array}{ll}
d_{11} & d_{21} \\
d_{12} & d_{22}
\end{array}\right]^{\prime}\left[\begin{array}{l}
\xi_{1, t-1} \\
\xi_{2, t-1}
\end{array}\right]\left[\begin{array}{ll}
\xi_{1, t-1} & \xi_{2, t-1}
\end{array}\right]\left[\begin{array}{ll}
d_{11} & d_{12} \\
d_{21} & d_{22}
\end{array}\right]
\end{aligned}
$$




$$
\begin{gathered}
=\left[\begin{array}{cc}
\gamma_{11}{ }^{2}+\gamma_{21}{ }^{2} & \gamma_{21} \gamma_{22} \\
\gamma_{21} \gamma_{22} & \gamma_{22}{ }^{2}
\end{array}\right]+\left[\begin{array}{ll}
\theta_{11} & \theta_{21} \\
\theta_{12} & \theta_{22}
\end{array}\right]\left[\begin{array}{cc}
u_{1, t-1}^{2} & u_{1, t-1} u_{2, t-1} \\
u_{1, t-1} u_{2, t-1} & u_{2, t-1}^{2}
\end{array}\right]\left[\begin{array}{ll}
\theta_{11} & \theta_{12} \\
\theta_{21} & \theta_{22}
\end{array}\right] \\
+\left[\begin{array}{ll}
\phi_{11} & \phi_{21} \\
\phi_{12} & \phi_{22}
\end{array}\right]\left[\begin{array}{cc}
h_{11, t-1} & h_{12, t-1} \\
h_{21, t-1} & h_{22, t-1}
\end{array}\right]\left[\begin{array}{ll}
\phi_{11} & \phi_{12} \\
\phi_{21} & \phi_{22}
\end{array}\right] \\
+\left[\begin{array}{ll}
d_{11} & d_{21} \\
d_{12} & d_{22}
\end{array}\right]\left[\begin{array}{cc}
\xi_{1, t-1}^{2} & \xi_{1, t-1} \xi_{2, t-1} \\
\xi_{1, t-1} \xi_{2, t-1} & \xi_{2, t-1}^{2}
\end{array}\right]\left[\begin{array}{ll}
d_{11} & d_{12} \\
d_{21} & d_{22}
\end{array}\right]
\end{gathered}
$$

